the vast Indian plain, which stretched for hundreds of miles in front. Here our expedition was to end and we were saddened that our existing trip was drawing to a close. We travelled back to Kathmandu by road and joined Dave Young, now out of hospital and recovering well from his injuries.

\section{Cameraman as well as doctor}

The trip was a memorable adventure for me. I had been fairly busy with the 12 team members and up to 130 porters. As well as illnesses there were many minor injuries, including bad bruises in a porter who had encountered an irritable yak on the trail. Local people also presented with more chronic problems, leg ulcers, eye infections, boils, and productive coughs.

Apart from my role as a doctor I was also assistant to the cameraman. I learnt techniques of sound recording and documentary film making, which was interesting and enjoyable, and the film we made, Thin Air White Water, was screened on Channel 4. My third major role was as stills photographer. The professional photographer we had planned to take had withdrawn at short notice, so official photography was designated to three of us with the most photographic experience. We have used the results for slide talks and to illustrate magazine articles about the expedition.

I thank Mr Mick Coyne for asking me to accompany the trip and Mr Nick Downie for teaching me about film making; Professor A V Hoffbrand for allowing me to take the leave; and Mrs Megan Evans for typing the manuscript.

Royal Free Hospital, London NW3 2QG

MARY GANCZAKOWSKI, BSC, MRCP, senior registrar in haematology

\title{
The forgotten war in the hidden valley
}

\author{
H D W POWELL
}

The Balkan Airways flight left Heathrow early afternoon on a Saturday in mid-March, first stop Sofia. Here we had a lengthy wait before travelling on. The Russian aeroplane was efficient but drab. Sofia Airport transit lounge has a marble floor, chandelier lights, and just basic tables and chairs. But on the lower floor is the cheapest duty free in Europe--not much good if you are flying to an Arabic country. We were-via Cairo and in an aeroplane with steadily decreasing occupancy. We landed at Khartoum at $330 \mathrm{am}$ and all $\mathbf{4 0}$ of us got off. Khartoum Airport was little changed since I was last there in 1971 and slow. We finally reached the Acropole Hotel and welcome beds as it grew light.

This trip was the first by a United Kingdom medical team to visit Eritrea. Two orthopaedic surgeons from Britain had been beforePeter Webb from Great Ormond Street and Robert Duke from Warwick, as well as a few orthopaedic visitors from various countries of western Europe. In March 1987 a whole medical team was asked to visit and our travelling was funded by International Medical Relief.

The Eritrean People's Liberation Front has been engaged in a struggle for independence against Ethiopia since 1961, and in 1981 it set up a base hospital of 1200 beds at Orotta. To work at Orotta was the genesis of our team's visit, and arrangements via International Medical Relief were made by the Eritrean Relief Association.

In Khartoum the relief association took over, dealing with police permits and arranging our flights to Port Sudan on the Red Sea. Woken at 430 am on the Tuesday we made the flight by two minutes; airline ticket arrangements had gone awry. Port Sudan was hot, breezy, and sandy. The association's guest house was our home for the next four days. Delay in travelling on was caused by the second and Unity Congress of the Eritrean People's Liberation Front and the Eritrean Liberation Front. (Years ago the two were in conflict.) This congress, attended by a worldwide audience, was in a specially built auditorium holding 2800 people and we could not travel into Eritrea until this was finished.

We finally arrived seven days after leaving London. Three quarters of an hour on a fast road in a Toyota Land Cruiser to Suakim, the old Turkish slaving port, where a massive vehicle repair camp occupies acres of sand. From then on the "road" is sand, rock, dry river bed, and wet river bed. Eleven hours at an average speed of $14 \mathrm{~km}$ an hour, almost always in second or third gear, rarely fourth, not infrequently first, and sometimes in four wheel drive. The flat desert country of the eastern Sudan was enlivened by a small locust swarm, creatures with bodies at least $6 \mathrm{~cm}$ long and leaping up to a metre or more in front of the vehicle. It was dark when we reached the drivers' camp for baked bread and jam and crossed a large dry river bed. In moonlight the country continued like a moonscape; mice and rabbits crossed the track and gradually we climbed.

\section{Gentle questions at the "frontier"}

Starting to splash up a wet river valley we climbed more, reaching the Eritrean checkpoint to be gently questioned at the "frontier"-name, country, and occupation. Orthopaedic surgeon was documented. Nurse was easy, but physiotherapist posed a linguistic problem, and prosthetist was I am sure beyond the guardsman. Then past three "camps" for Ethiopian prisoners of

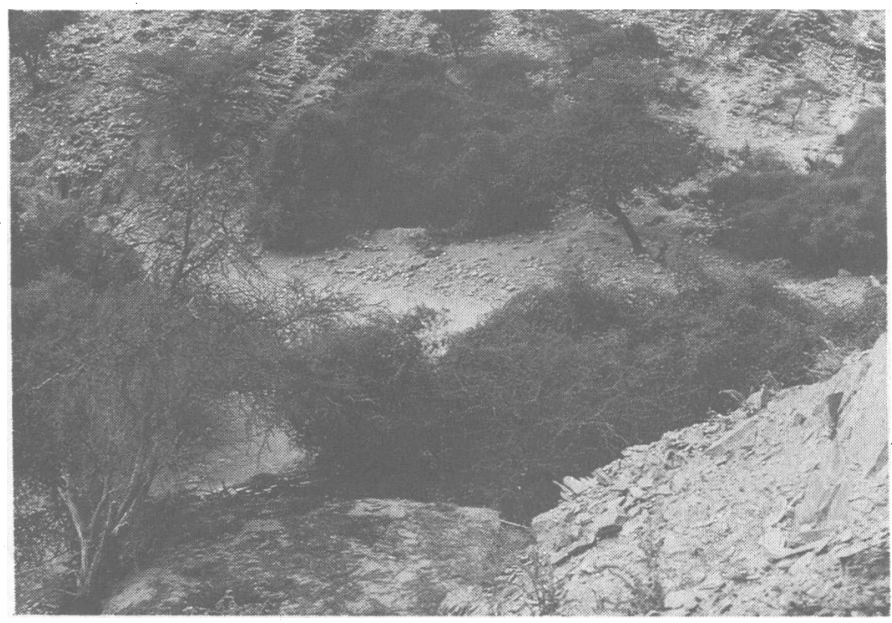

The medical guest house is under the nearest thorn tree and its cookhouse under the far one. 
war equipped with badminton nets strung across the track, and we really climbed-300 m or more up a massive hairpin bend "road". massively hewn out of rock. (It was only later that we discovered that this was done entirely by human muscle plus some small compressor machines. When it was hewn the Eritreans had no earth moving equipment.) Up at perhaps $2000 \mathrm{~m}$ we were rewarded by a splendid view of the Southern Cross. The Pole Star and the Plough were equally visible and there cannot be many places in the world where you can see both at the same time. I have done so once before in Kano in northern Nigeria.

Then down to a long rocky valley and lights and at one in the morning we reached the medical guest house still full of folk from the congress, and bed was more than welcome. So here we were in Orotta-a physiotherapist, senior nurse, prosthetist, and orthopaedic surgeon. You will not find Orotta on any map. Like Eritrea (a non-country to the United Nations) it does not exist. In 1981 this was a barren rocky valley in the far north west of what had been Eritrea, uninhabited except by nomads with herds of goats and cows, largely waterless; flash floods come in June and July and there must be enough underground water to sustain numerous large acacia thorn trees. Spread over $5 \mathrm{~km}$ in this barren and rugged wilderness, where the schist rock valley sides rise often extremely steeply and the highest point in the area is up to $2800 \mathrm{~m}$, is this remarkable hospital of up to 1200 beds. Water is trucked in by tankers from a dam some distance away, offloaded into concrete tanks at points in the valley, and then piped to wherever it is needed. Electricity is from one main and several subsidiary generators spread up and down the valley. Light comes on at 6 o'clock in the evenings and continues as long as the theatres require it; otherwise it is torchlight.

\section{Mud walls and Italian machinery}

All the buildings are small and hidden into the hillsides, dug down and then in. Concrete or mud floors support drystone walling. Roofs are massive tree trunks, often tree trunk supported, covered with sacking and brushwood sufficient to be waterproof. The walls are a mixture of mud and lime, some plaster covered. Most of the buildings have one or more large overhanging thorn trees outside. From the air the buildings must be invisible; from the valley floor they are almost equally impossible to see unless you are very close. By every building is a dugout hewn down into the rock.

High up in the valley that curves like an extended snake is the central pharmacy. Five hundred plastic bags with intravenous solutions are produced every night to be dispatched all over free Eritrea as well as to the base hospital. Very recently installed is the one tonne machine for antibiotic production, turning imported powder into pills and capsules. This, the very latest Italian machine-Eritrea's 70 years under Italian colonial rule has left

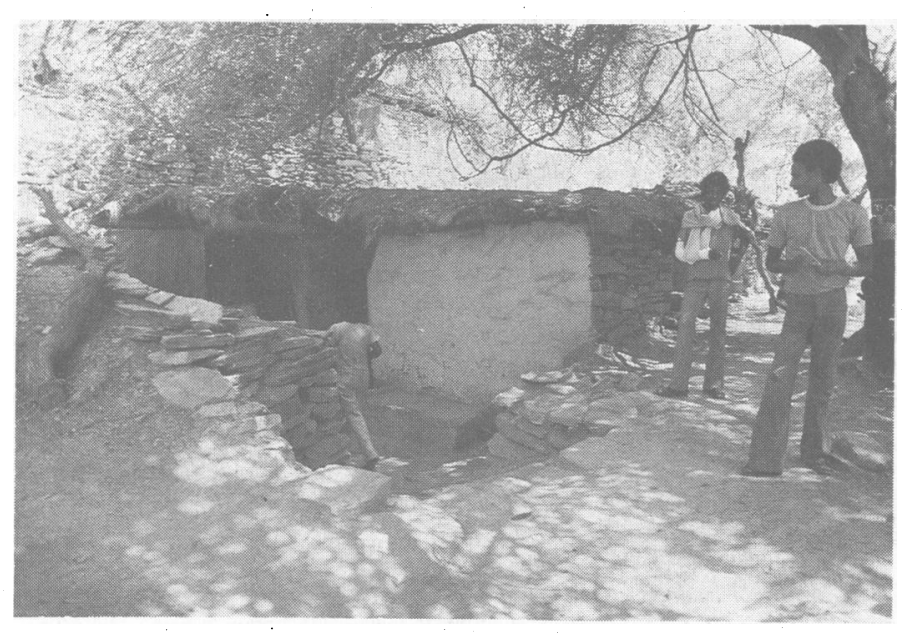

Entrance to one of the orthopaedic wards.

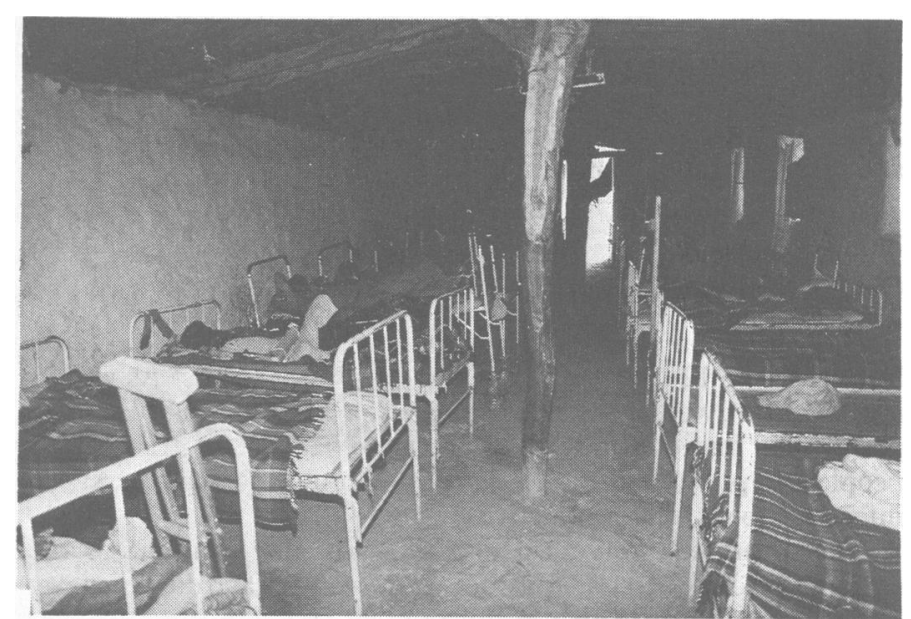

An orthopaedic ward.

many reminders-was trucked up from the Sudan, the last $30 \mathrm{~m}$ requiring manhandling up a series of rollers to its present site. Now installed, one glass sheet has been broken, but this is not affecting its producing capacity. Basic antibiotics can now be manufactured here and distributed throughout the country.

A series of ward blocks spread down the valley. Each department has two, three, or four separated buildings, all built to the same half hidden pattern and cleverly camouflaged. Neurosurgery and neurology have three wards; then there are the cardiovascular department wards, which seemed to do most of the general surgery. (While we were there a patient arrived all the way from Saudi Arabia where he had seen several medical advisers. Dissatisfied, he had made the long and difficult journey up to Orotta to have his subacute intestinal obstruction expertly relieved by the surgeon in charge of the department.) The orthopaedic unit has three wards, one not in use when we were there, plus a purpose built recovery unit, its doors made from old packing cases. Most of the work is the result of war injury from every known form of weaponry, including napalm.

The fighters are all volunteers - unlike the Ethiopian forces, who are mainly conscripted-and $30 \%$ are women. In the orthopaedic unit there is no separation of the sexes. Most of the injured have had first aid treatment near the front and probably stay in one of the district hospitals before reaching Orotta-anything up to 10 days after injury. If a plaster change is needed a standard orthopaedic table sits outside the ward under a thorn tree, not infrequently used for spicas of both hip and shoulder. Elsewhere in tropical countries I have met resistance to the use of body plaster casts because of the heat. Here in Orotta they are accepted when needed. The wards are cool and there is much shade under the thorn trees.

\section{Theatres panelled with mosaics}

Passing the medical guest house, complete with separate shower and 100 room with a flush system, one comes to the $x$ ray department, one of whose three machines was liberated from the enemy and still works. We then arrive at the theatre block. High on its dry stone wall support and with two windmills outside for wind power, this is a remarkable place. Thorn trees screen the outside and the two solar panels on the roof provide extra light power, these being covered with blankets-and therefore less efficient-as a camouflage necessity. Once in, in theatre shoes, we are in another world. The theatres, which would not disgrace the Western World, have mosaic panelling half way up the walls. This panelling was liberated when an Eritrean town was temporarily in Eritrean hands, along with a mass of military equipment. The tables are modern, as are the movable lights. In addition there is strip lighting from the generator. There is a separate recovery room, although it is easier and safer to lay the stretchers on the floor. Anaesthesia by nurse anaesthetists lacks any cylinders and therefore oxygen. For the same reason orthopaedic power tools have to be electric, not worked by 
compressed air. Much use is made of the Oxford McIntosh Vapouriser, ketamine, ether, halothane, and intraveous drugs. The first procedure we witnessed was an open anterior thoracotomy by sternotomy for a malignant tumour-hardly a likely scene in a valley unoccupied until six years ago.

We pass the main generator, the central bakery using one and a half tonnes of sorghum flour each day, and around more valley bends we reach the dental and maxillofacial unit. The dental surgery is spick and span and the woman doctor, a graduate from Sofia, not only does some excellent facial reconstructions but also copes with major plastic work. The maternity and gynaecological department has $\mathbf{5 0 0}$ deliveries a year, mostly patients with complications, and inevitably the most difficult gynaecological procedure is the vesicovaginal fistula. It is then a lengthy walk to the steep narrow sided valley for medicine and paediatrics. Tropical diseases are inevitably though not predominantly the problem, the hot dry climate and barren rocky valley not being conducive to many diseases. The department does have the longest bed in the world-a raised stone platform down each side, blanket covered, on each of which at least 25 can sleep. Most patients are convalescing and waiting to be fit enough to return to the front line.

\section{Basketball on one leg}

It is a considerable distance further on to the modern prosthetic workshop equipped with brand new West German machinery. There are 500 amputees in the hospital valley, all single amputees, as the 150 double amputees and those with paraplegia are in the "hospital" by the guest house in Port Sudan. Those folk cannot return to Eritrea until the towns and cities are back in Eritrean hands. A single leg amputee may be seen playing basketball on his single good leg, but the more severely handicapped could not cope with the wild country in the mountains.

Most of the patients in the hospital, especially in the orthopaedic department, are war injured. Every known method of maiming is available to the Eritrean forces. For many months now fighting in the front line has been quiet and casualties have been few. Most of those we saw are from commando type units who operate behind the front line complete with medical teams and portable $x$ ray apparatus; some of the teams carry a portable microscope. We saw one of these in use in the central laboratory, British designed, collapsible, and easily carried. What percentage of the injured fighters survive to reach the base hospital is unknown. The journey may take many days. Surgery is at best second stage or reconstructive. There is a surprising amount of modern equipment for internal fixation. Sometimes the leap from conservative management to modern internal fixation has been made too fast. Some of the implants are cast offs from western Europe. Fifty cm Kuntscher nails, a whole bundle of them, are no use to people of the stature of

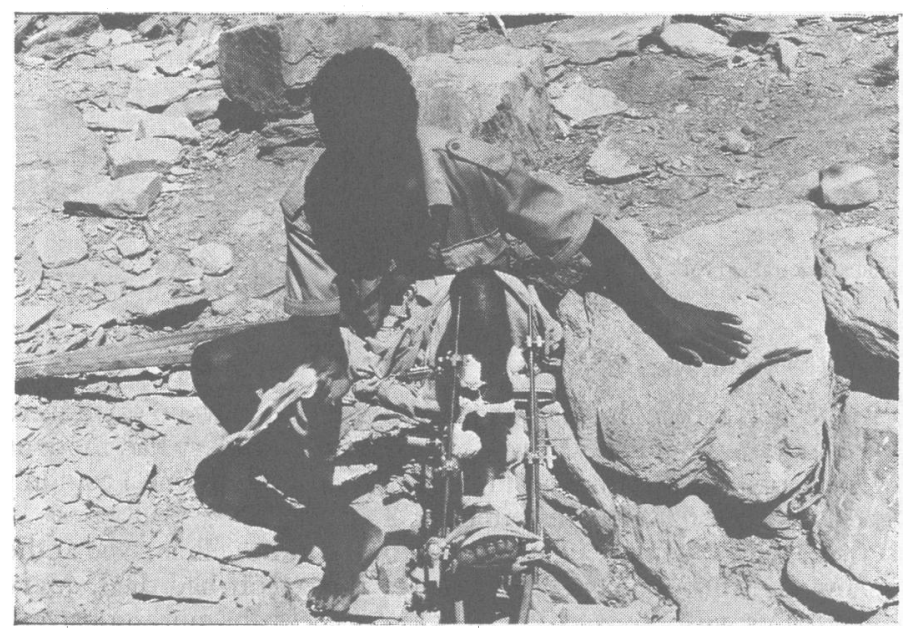

Hoffmann external fixator on one of the fighters.

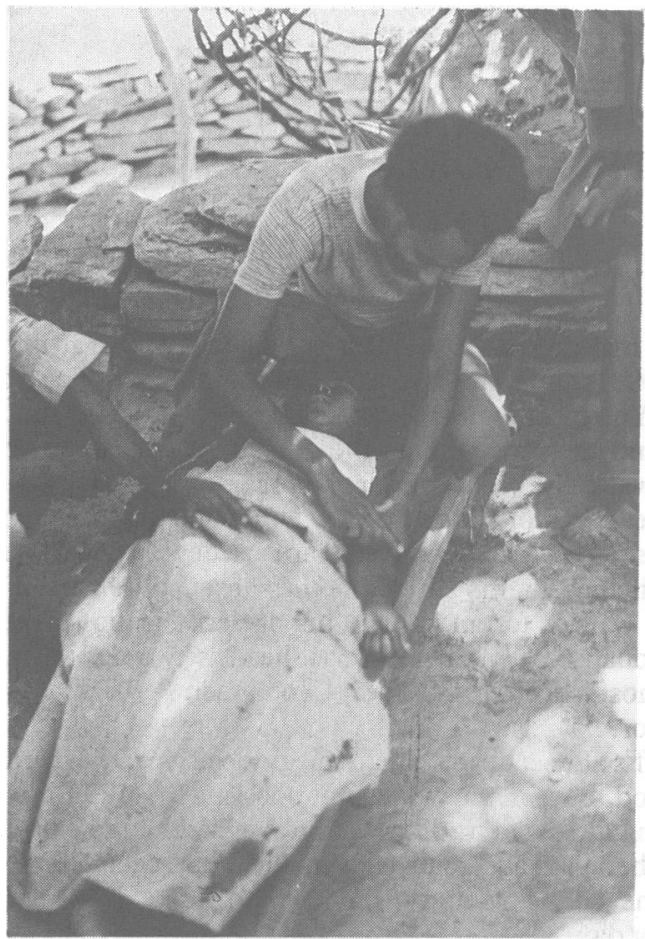

Treating a snakebite with antivenom.

the Eritreans. They might suit the femora of the Dinkas in the southern Sudan. Much of the orthopaedic operating while I was there was in the hands of a nurse, trained as anaesthetist and in charge of the theatres, then trained as an orthopaedic surgeon. He obviously had considerable experience of operating near the front line and had acquired a remarkable knowledge of modern orthopaedic armamentarium. In his case this could have been only from others in free Eritrea or from books and journals. The inevitable gaps in his knowledge was one reason why an orthopaedic visitor was requested.

Hospital valley is not short of food. Sorghum, much of it imported, is a major item of diet. The Italian influence yielded the macaroni and spaghetti. An abundance of eggs and vegetables is trucked down from other parts of free Eritrea, especially spinach. The beetroot, offloaded one day from a lorry, was the size of footballs and very edible. Certainly everyone in the valley was adequately fed and we understood this also applied to the fighters. How the majority of the semitroglodyte population fare for diet was less clear. There were many children in the valley and they certainly seemed well nourished.

Such then is a brief impression of a remarkable people in a remarkable place. They are intensely determined on independence. As they adapt to their barren surroundings they display determination and initiative combined with inventiveness and adaptability. It is a privilege to be able to visit them and to work there.

I am grateful to International Medical Relief and its medical director, Dr John Foran, and to the Eritrean Relief Association and to the Eritrean People's Liberation Front, who looked after us so well during our visit.

My colleagues in the team were Anne-Marie Hassenkamp, deputy head physiotherapist at the National Orthopaedic Hospital, London; Fiona Sherriffs, clinical specialist in infection control at the Royal National Orthopaedic Hospital; and Norman Govan, senior lecturer at the National Centre for Training and Education in Prosthetics and Orthotics at the University of Strathclyde.

High Wycombe, Bucks HP15 6LJ

H D W POWELL, MB, FRCs, consultant orthopaedic surgeon

Correspondence to: Ravensmere, Cryers Hill, High Wycombe, Bucks HP15 6LJ. 